\title{
Cause and Effect in the Undergraduate Education Crisis
}

\author{
Ray N. Nitzsche \\ Parks College of Saint Louis University
}

\begin{abstract}
This paper addresses the cause and effect relationship between the current emphasis on research and many of the present problems in undergraduate engineering education.
\end{abstract}

\section{The Cause}

We have all heard so much lately about "the crisis in undergraduate education," "the problem with undergraduate education," or, more formally stated, the need to "reaffirm the undergraduate experience and rediscover the essentialness of teaching." 1 We hear of poorly equipped graduates, student retention problems, ${ }^{2}$ poor student advising, ${ }^{3}$ etc. These are effects. There has been a great deal of fingerpointing, and a number of solutions to each of the specific problems have been proposed. That is, a number of separate and specific causes have been proposed. Actually, graduate level education has some of the same deficiencies; however, due to the difference in the nature of graduate and undergraduate education, especially at the doctoral level, the effects are not as severe and thus are not as evident.

What has gone wrong? What is the cause? Is it one thing or several? Well, I think I know what one very significant cause is. A significant cause is research, or let's call it the overemphasis on research. By research I mean the sort of research, usually "cutting edge" research, which gains one grants, publications, and promotions at today's universities. In addition, I use the word research as a collective term because, of course, it's not the research itself, the dictionary definition, which is the problem. Research is necessary and good. It's what research does to attract the wrong type of people to universities, to negatively affect the activities of those at universities, to negatively affect the focus of administrators at universities, etc. In fact, research has caused us to lose sight of our basic function. We have drifted away from our real purpose. We have moved away from what we are best equipped to do and what we do best.

I'm sure my idea is not unique. In fact, there are probably a large number of people who would agree. In addition, I'm sure many of the ideas and observations I present in what follows have occurred to many others. Some can be found in recent publications. My only addition may be that I have collected and organized the various ideas and observations and have added some logic to the thought in this area.

\section{Signs That Research Is Overemphasized}

Before we investigate this cause and its effects, let's look at some of the signs, some proof, that research has indeed become overemphasized. I offer the following list. As you read this list, note how many of the present conditions or methods of operation at our universities did not exist or had much less importance some years ago but toward which we have drifted, to the extent that they now are the accepted mode of operation. We usually no longer question their validity or necessity; furthermore, we no longer consider their effects upon ourselves and our students. 
1. We all know of the faculty member who is a poor teacher, maybe even terrible, who publishes the required number of papers, whatever that number might be, and is tenured. At the same time we know of the good teacher who does not publish the required number and is not tenured or promoted.

2. Young faculty are immediately instructed and pressured to develop a research program rather than being immediately instructed in ways to improve and establish their teaching skills.

3. Most universities have an office called something like "The Office of Research Services" whose purpose is to aid faculty in writing proposals leading to grants and in managing these research contracts. But, how many universities have an office called something like "The Office of Teaching Services" to aid faculty in seeking and implementing ways of improving their teaching? If they do have each type of office, what is the relative level of funding and importance?

4. I have two young colleagues who, after a couple of years of concentrating on their teaching, resulting in good teaching evaluations, were told that they must publish a given number of papers to obtain tenure. They responded over the next few years with the necessary research and the appropriate number of papers. During this period of research and publishing, both were concerned about their teaching evaluations since they realized they were spending too much of their time on their research. Indeed, their teaching evaluations decreased significantly. However, they received tenure.

5. Our universities and certainly most of the research type faculty tend to view all students as if they're going to be doing research when they graduate. These faculty are so involved in research that their view of the engineering and science fields is distorted and they somehow think that everyone is doing research; the basis of everything is research. We sometimes even make a significant effort at getting undergraduates involved in research.

6. We have reached a situation where it seems that most people both inside and outside of our universities feel that universities are where research is and should be done, all research. Anytime an advance is needed in some technical area, usually in a crisis situation, everyone turns to our universities. For example, at present everyone seems to be depending upon our universities to keep the United States competitive in the world market.

7. The number of teaching type faculty is decreasing and the number of research type faculty is increasing.

8. Some of our basically or even completely undergraduate institutions have been drawn into adopting stringent research and publication requirements for their faculty. Furthermore, the requirement that this research be on the cutting edge is nearly as strong as it is at the large, research, graduate degree granting universities. I, and some others I suppose, refer to this as the "MIT Syndrome." Everyone wants to be, or thinks they should be, MIT.

9. At present, the title of scholar is very closely associated with publishing. Scholarship is commonly thought to be the act of publishing. 


\section{Reasons for Research Being Overemphasized}

Now let's look at how research became overemphasized. Let's investigate the origin of this cause. I think there are several interrelated reasons for this overemphasis, which I offer below.

1. Many research type faculty come to universities because they can do research in the area(s) of their choice, free of the restrictions they would encounter in an industrial or research laboratory environment. They do not come to teach, develop, and guide students. In many cases they cannot even cope with an industrial environment, or perhaps a university is the only place where they can find employment. Again, they did not come to teach. Consequently, they support, consciously or subconsciously, the idea that research is an essential part of a faculty members duties, even the idea that research and teaching are inseparable. It's simply a selfish act on their part although most are probably not even aware of it. Many people cannot separate what they want from what they feel is right. In addition, this support of research often involves membership on rank and tenure committees where they can further insure that the importance of research is promulgated. This last condition is bolstered to some degree by the fact that rank and tenure committees are made up of ranked faculty who, of course, most often, achieved this rank through research. Thus, an inordinate number of research supporters are on rank and tenure committees.

2. People with ego problems tend to gravitate toward universities. To these people ideas such as rank, title, research status, and peer review hold a great deal of importance. Success using these measures is not gained by good teaching or other endeavors such as advising, at least not with the flawed system which is presently in place. Consequently, these faculty value and support research, which leads to the same results described in item 1 directly above.

3. Since research usually means grants, money, university administrators fully support research being very important. They are glad to see this research "carrot" held out in front of faculty, especially young faculty, as the means toward rank and tenure.

4. Government and industry support the idea of research on university campuses because we do it economically with our cheap, graduate student labor and low-salaried faculty members and because universities are a good source of intelligent, hardworking, talented people.

5. A significant research and publication output from a university leads to fame and notoriety for this university. This is welcomed by most faculty and certainly welcomed by the university's administrators. Indeed, this leads to an ever increasing ability to attract more research funds in a sort of snowball effect. It also has some effect on attracting students to the university.

6. Research output is easier to measure than most other faculty duties. It is more easily quantified. One can make a list of grants received or papers published. On the other hand, for example, we have not had a comparable way of measuring teaching ability. Consequently, since it is human nature to tend to base an evaluation upon those properties which can be measured, research output has grown in importance in making faculty evaluations.

7. Three serious misconceptions are widely held:

a) A faculty member must do research to be a good teacher. 
b) All a faculty member needs to perform his or her function is a thorough knowledge of his or her field. ${ }^{4}$

c) Simply presenting the subject material is teaching.

\section{Effects of Overemphasizing Research}

The overemphasis on research causes a number of problems, has a number of effects. As you read the following list of these effects, note how many have a detrimental effect upon advising, retention, quality of teaching, etc., that is, upon undergraduate education.

1. The first problem in this list must be that most good researchers are not good teachers. We all know this from our own experience. We all know of our own college days when we saw a high correlation between the active researcher and the poor teacher. This, according to Felder, ${ }^{5}$ has been substantiated by educational research. It should be pointed out, also stated by Felder,

that there are a few who are capable of doing a good job of both teaching and research, but, in general, this is not true.

2. Again from Felder, researchers have a different personality than teachers and consequently are not as interested in the necessary mentoring, advising, etc., roles of a faculty member.

3. Forcing everyone, in particular I think of young faculty, to follow the same path leads to competition and all of its associated evils. To explain, if one starts keeping score in any way, number of papers, number of grants, etc., people will start competing. This leads to uncooperativeness, jealousy, etc.

4. People are writing papers because they have to write papers. This leads to the filling of journals with worthless papers.

5. It doesn't matter how technically competent a faculty member is if he or she doesn't or can't or doesn't even want to pass his or her knowledge along to students. This faculty member is of no value to a university.

6. In order for faculty, both young and old, to devote the time which they must to research, they must nearly devote their lives to their research work. Consequently, it is less likely that they will become the well rounded, reachable, concerned, personable people which they must be to be the mentors, role models, and character builders which they should be.

7. The most important courses for students are the basic courses; however, these are the courses where research activity has the least effect upon a person's teaching ability.

8. Peer review stifles creativity.

9. Faculty members need more than intelligence and the ability to do research. They need special skills and attributes like very good communication skills, concern for students, a desire to communicate with students, friendliness, a basic nature and personality that will 
command respect and trust, etc. The greater proportion of research type faculty members do not have these attributes. 5

\section{Benefits of Research?}

I could not, and should not, write a paper on this subject without considering the possibility that perhaps the benefits of research at universities outweigh the various detriments given above and that thus the existing condition should remain. To this end, consider the following list of common expressions of support of research at universities and the accompanying rebuttals.

1. Research output increases the fame and notoriety of a university. This is true; however, most of this fame and notoriety is the result of judgments by the university's peers. They, at present, are basing their judgments mainly upon research activity. Also, the general population is most aware of and thus most impressed by the research done by the university. Consequently, this fame and notoriety is the result of judgments based upon only one of several factors. It does not include, most importantly, the quality of the education received by the university's students.

2. The graduates of research universities are highly sought by industry. This is true except that due to the attraction of the notoriety of these universities, the better, more intelligent, students enter these universities. Obviously, their graduates will be intelligent and valuable.

Their greater value is not a result of the fact that they received better instruction but a result of the fact that they were more intelligent when they entered.

3. Research enhances teaching; the two are inseparable. This statement was certainly negated by Felder in Reference 5. I would like to further point out that from the fact that some faculty do both well, it does not follow that teaching and research are inseparable, nor does it necessarily follow that research supports teaching. It can mean that they simply happen to have the talents and desire to do both. In addition, the present thinking among many is that the only way for a faculty member's teaching to remain current and exciting and possess vitality is for this faculty member to do cutting edge research and publish the results. However, there are a myriad of ways for faculty members' teaching to remain current and exciting, as many ways as there are different people, different personalities. In fact, realizing this is one of the keys to proper faculty development.

\section{The greater the research and publication output of a university, the better the} university. This certainly seems to be the present opinion, and most universities are in a constant struggle to increase their research output, thinking that this is the path to becoming better. Actually, a high research and publication output indicates simply that a university has succeeded in collecting a large number of faculty who are good at research and publication and/or have been successful in inducing existing faculty to increase their research output. Consequently, until a beneficial connection is made between research output and the other necessary functions of a university, in particular those functions which affect students, one cannot say that increasing the research output of a university makes it better. 


\section{Our True Purpose}

I stated earlier that our overemphasis on research has made us lose sight of our true purpose. To explain, let's begin by defining the purpose of a university. Stated in the simplest terms, a university is a place or organization which collects and holds information and skills, both in the form of written materials, e.g., the library, and in the form of the information, ideas, and talents contained in the minds of its faculty, and to which people (students) go to obtain (learn) this information or these skills. Another way to explain the characteristics and purpose of a college or university is by noting the analogy between a university and a library. That is, a library is in the continuous process of obtaining, sorting, classifying, and storing knowledge and making this information available to those who seek it. In fact, a good library is actively involved in disseminating this knowledge and making it as easy as possible for a person to obtain what he or she seeks. These are the same basic functions or duties of a university, at least the most important functions.

Having this description of a university and the fact that the faculty are the basis of a university, we see that a faculty member must perform the three basic functions described above and attributed to both a university and a library. That is, a faculty member must perform the three basic functions of acquiring, holding, and delivering knowledge. And these functions must be done continuously. However, our overemphasis on research has caused us to devote too much time and effort and resources to the first function and has caused us to attract faculty whose main interest and talents are in the first function. Naturally, the other functions suffer. Furthermore, this problem is compounded by the fact that research, as it is now defined at most universities, is only a portion of the first function because the present aim of research at universities is the acquisition of new knowledge when, in fact, the acquisition of any knowledge, new or old, is included in this function.

The purpose described above can really be summarized with one word. This word is learning. Acquiring and holding knowledge is learning, learning on the part of the faculty member. Delivering this knowledge involves learning, learning on the part of the student. A faculty member should love to learn, should love to see others learn, should love to make others love to learn. Being a scholar and scholarship are, according to the dictionary definitions, associated with learning. A faculty member should love ideas for their own sake. A faculty member should be a person who welcomes a life of obtaining and possessing knowledge, one who enjoys "reading the dusty old books", as well as keeping abreast of the latest developments in his or her field, one who expects to be a repository of knowledge, sort of serving the same purpose as a library. Also, a faculty member should have a desire, a sense of serving, to deliver, in the best way possible, this knowledge to others who come to him or her to learn, again like a library. This desire stems from his or her wish to have the students put the knowledge to use in their lives and in their own service to mankind and to ensure that the knowledge will be passed on and not lost, passed on especially to those who may themselves become teachers.

If a university and its faculty operate in this way, they are fulfilling their basic purpose. They will then be successful. However, success is being measured in terms of research activity. This results in an overemphasis on research, causing many detrimental effects on our undergraduates' education. Hence, the crisis in undergraduate education. 


\section{References}

1. Boyer, Ernest L., "Rediscovering the Center," ASEE Prism, September 1993, pp. 20-25.

2. Ercolano, Vincent, "From Sleep 101 to Success 101," ASEE Prism, September 1995, pp. 24-29.

3. Panitz, Beth, "Academic Advising: Clearing Paths to Success," ASEE Prism, February 1995, pp. 18-21.

4. $\quad$ "Instructors and Courses That Really Rate," ASEE Prism, November 1995, p. 10.

5. Felder, Richard M., "The Myth of the Superhuman Professor," Journal of Engineering Education, April 1994, pp. 105-110.

RAY N. NITZSCHE

Dr. Nitzsche received his B.S., M.S., and Ph.D. degrees from the Department of Theoretical and Applied Mechanics at the University of Illinois. He has over eight years of industrial experience, with the bulk of this work being in the area of finite element analysis, and a total of eighteen years of teaching and research experience at the University of Missouri-Rolla and Parks College. 